\title{
La extraordinaria sequía de 1924: Crisis socio-ecológica e irrupción del poder militar en Chile ${ }^{1}$
}

\section{The extraordinary drought of 1924: Socio-ecological crisis and irruption of military power in Chile $^{1}$}

\author{
Pablo Camus² (i) y Fabián Jaksic ${ }^{3}$ (i)
}

\begin{abstract}
RESUMEN
Las interacciones entre clima e historia no han sido suficientemente estudiadas pero han adquirido gran relevancia con la actual crisis climática global. Buena parte del territorio de Chile se halla bajo la influencia del fenómeno oceánico-atmosférico El Niño-Oscilación del Sur (que produce ya sea sequías severas o años extremadamente lluviosos), pero no se ha estudiado qué impactos ha producido en las relaciones políticas, económicas y sociales en nuestro país. Esta investigación se basa en la bibliografía referida a la crisis de 1924 y especialmente en las fuentes de la época tales como la prensa, las sesiones del Congreso Nacional y los comunicados del gobierno. Este trabajo explora la crisis de 1924 desde un punto de vista socio-ecológico y propone que la mayor sequía en doscientos años bien pudo haber incrementado el descontento social, resultando la irrupción del poder militar en Chile y las matanzas de Marusia y La Coruña.
\end{abstract}

Palabras clave: Clima, Historia, Sequía, Movimientos Sociales

\begin{abstract}
The interactions between climate and history have been insufficiently studied, but have acquired new urgency in the context of the current global climate crisis. Most Chilean territory is affected by the oceanic-atmospheric El Niño-Southern Oscillation, but the political, economic and social impacts of this climate fluctuation (that results in either severe droughts or extremely wet years) have not been investigated in our country. This research is based on the analysis of the literature referring to the 1924 Chilean political crisis --especially period's sources such as press releases, sessions of the National Congress, and central government statements. This article explores the aforementioned political crisis from a socio-ecological perspective, proposing that the harshest drought recorded over two centuries was a major underlying factor of the increased social unrest that preceded the irruption of military power in Chile, as well as the massacres of Marusia and La Coruña.
\end{abstract}

Keywords: Climate, History, Drought, Social Movements

Agradecemos al Proyecto ANID 1180537 ¿Despotismo hidráulico? Irrigación, organización social y conflictos por el agua en una sociedad en transición al capitalismo: Valle central de Chile y CONICYT PIA/BASAL FBOOO2 al Center of Applied Ecology and Sustainability (CAPES), Pontificia Universidad Católica de Chile. 


\section{Introducción}

La crisis ambiental contemporánea ha originado un creciente interés por comprender los fenómenos climáticos y meteorológicos, pero también sus repercusiones políticas, sociales y económicas. Diversos estudios han intentado demostrar las relaciones entre disturbios sociales y eventos climáticos extremos (Rotberg \& Rabb, 1981; Arriero, 1984; Black et al., 2013; Lamb, 1994; Fagan, 2000; Hsiang et al., 2011; Alberola-Romá, 2012; Beresford-Jones, 2014; Bellemare, 2015; White et al., 2017; Pribyl, 2017). El historiador del clima Emanuel Le Roy Ladurie ha llamado a interesarse "por lo que es la materia misma de los disturbios de subsistencias y de las revoluciones consiguientes: la influencia del clima o más exactamente de la meteorología sobre las cosechas, las acciones populares para la obtención del grano ante los problemas derivados de los temporales y sobre ésta la politización implícita o explícita del movimiento plebeyo" (Le Roy, 2017). Los ejemplos son innumerables. Recientemente, en 2008, el aumento en el precio de los alimentos habría desencadenado disturbios en al menos treinta países (Hauenstein et al., 2009).

Considerando lo anterior, en este trabajo nos interesa profundizar en la historia de las relaciones entre eventos climáticos inusuales, como una sequía extrema, con los procesos económicos, sociales y políticos acaecidos en el país. Desde esta perspectiva nos preguntamos y analizamos las concomitancias y los posibles efectos precipitantes de la extraordinaria sequía de 1924 en los profundos cambios experimentados por Chile a partir de ese año. ¿Pudo la sequía extrema y el consecuente encarecimiento de los alimentos y de la vida catalizar la crisis desencadenada a partir del 11 de septiembre de 1924?, cuando ya los efectos catastróficos de la escasez de agua más extrema en dos siglos se dejaban sentir en la población, incluso en el nivel de vida del estamento militar. ¿Pudo la muerte del ganado mayor y menor por falta de pasto y la ruina de los cultivos en las zonas de secano costero propiciar un alza en el costo de la vida producto de la carencia de alimentos básicos y desencadenar así un malestar generalizado que se expresó en demandas por mejores salarios, sublevaciones, huelgas y matanzas? ¿Pudo influir la sequía y el horizonte de hambre como elemento atemorizante y precipitante del ruido de sables y de la irrupción de los militares? ¿hubo también otros factores como el acaparamiento y la especulación que finalmente determinaron el curso de los acontecimientos? O bien, ¿de que manera la sequía actuó en un momento de crisis dinamizando ciertas coyunturas críticas que estaban allí pero que no estallaban?

No desconocemos, por supuesto, la extensa crisis socio/política/económica que afectaba al país como tampoco las luchas y matanzas obreras de las primeras décadas del siglo XX en respuesta a sus demandas y aspiraciones por mejores condiciones de vida, como tampoco nos alineamos con un determinismo geográfico. Pero es interesante constatar y analizar que todo aquello se produjo en un momento de crisis climática extrema, como lo fue la sequía más intensa desde los inicios de la República hasta el presente, pero también en un escenario en que el precio internacional del trigo y la harina incrementó las exportaciones, de acuerdo a las estadísticas presentadas por Cariola y Sunkel, pese a la hambruna que se desencadenaba en el país (Cariola y Sunkel, 1982).

En efecto, los estamentos militares y otros amplios sectores de la sociedad venían reclamando por mejoras salariales y derechos sociales y políticos, al menos desde principios del siglo XX (Charlin, 1970; Grez Toso, 1997; DeShazo, 2007; Garcés, 2003). Es cierto que antes de 1924 hubo años de conspiraciones, huelgas y matanzas obreras incluso poco antes como la de San Grego- 
rio. Sin embargo, ¿por qué se expresaron los militares en el mentado ruido de sables justamente cuando la sequía comenzaba a dibujarse con toda su intensidad al finalizar el invierno de 1924 ? Lo cierto es que hacia agosto y septiembre de ese año era evidente para la sociedad nacional que se trataba del período más seco desde que se tenían registros más o menos confiables y que la mortalidad de cabezas de ganado y la ruina de los cultivos ya era una cosa difícilmente reversible, pues a esa altura del año era prácticamente improbable que precipitara de un modo tal que pudiese compensar la falta de agua. Solo quedaba acudir a la "suerte" o a las "rogativas a San Isidro" para que los próximos años fuesen más lluviosos, de lo contrario los efectos de la sequía finalmente se dejarían sentir por muchos años.

El 31 de julio de 1924, unos meses antes de la disolución militar del Congreso Nacional, mientras se discutía un impuesto a los fósforos para abastecer las escuálidas arcas fiscales, José Dolores Vásquez, Diputado Radical por Copiapó, Chañaral, Vallenar y Freirina, denunció la seriedad del problema de la falta de precipitaciones y la consecuente sequía y carencia de alimentos indicando: "el porvenir nos muestra a corto plazo los siniestros contornos de una hambruna terrible debida a las malas cosechas del año en curso.... estamos amenazados de la catástrofe del hambre por obra de la sequía". En medio de las agitaciones políticas y sociales, el desprestigio del parlamento, las amenazas militares y la grave crisis económica que afectaba al país, el diputado Vásquez lamentaba finalmente que "no se haya dado todavía a la publicidad un plan de gobierno que tienda, en forma ostensible y clarísima, a hacer ver al país que los hombres que realmente lo conducen están realmente empeñados en prevenir esta catástrofe que se acerca a gran marcha en nuestro pueblo y que seguramente va a ocasionar convulsiones inevitables"4.

En 2 de agosto una nota editorial del diario La Federación Obrera indicaba que el hambre ya estaba ante las puertas de los hogares de las familias proletarias chilenas. La falta de lluvias y la situación financiera del país gravitaría sobre la clase asalariada "con todo el mayor efecto de sus funestas consecuencias" ${ }^{5}$. En seguida, el periódico reclamaba que mientras se realizaban gastos inútiles para recibir autoridades políticas extranjeras, la miseria "va tendiendo su negro manto sobre los pueblos del país y de sus habitantes menesterosos" ${ }^{\prime}$. Asimismo, el 5 de agosto denunciaban que 113.700 toneladas de cereales habían sido exportadas en el último tiempo y que se estaba especulando con la miseria,

"para ir a satisfacer necesidades de pueblos extranjeros mientras el nuestro, con la huida de sus productos, se siente gravemente amenazado con las torturas del hambre. La avaricia de los capitalistas busca mejores precios para los cereales, sin importarles mucho ni poco que sus compatriotas en general y los trabajadores en particular, terminen por morirse de hambre! Nos alarmamos con la gran mortalidad, una de las mayores del mundo; nos ruborizamos de que los robos se sucedan con tanta frecuencia pero no nos asombramos que 113.700 toneladas de cereales salgan de nuestro país, amenazado por el hambre, para ir a buscar mejores precios en lejanas tierras. A esta grave situación que se ve venir debemos agregar la persistente sequía, aliada esta vez de los especuladores; lo cual debiera ser

Sesiones del Congreso Nacional. 49 sesión en 31 de julio de 1924

"El hambre ante las puerta de los hogares de las familias proletaria chilenas". La Federación Obrera, Santiago, Chile, 2 de agosto de 1924. Ver también, "El espectro del hambre". La Defensa Obrera, Tocopilla, Chile, 2 de agosto de 1924, p. 1.

6 "El hambre ante las puerta de los hogares de las familias proletaria chilenas". La Federación Obrera, Santiago, Chile, 2 de agosto de 1924. Ver también, “El espectro del hambre". La Defensa Obrera, Tocopilla, Chile, 2 de agosto de 1924, p. 1. 
un motivo poderoso para que se impidiera exportar productos que no se obtendrán en el presente año agrícola ${ }^{7 "}$.

\section{Observaciones sobre la magnitud de la sequía de 1924: sus efectos económicos y sociales}

Desde la distancia, y de acuerdo a los datos sobre precipitaciones en Santiago de Chile (entre 1824 y 2018) que hemos podido recopilar, el año de 1924 llovieron $66 \mathrm{~mm}$. Se trata del período en que menos precipitó en prácticamente doscientos años, poco menos que en 1968, año en que cayeron $67,6 \mathrm{~mm}$. Así, hasta ahora, 1924 ha sido entonces el momento más seco de nuestra historia republicana.

Figura No 1

Lluvias en Santiago de Chile, 1824 - 2017

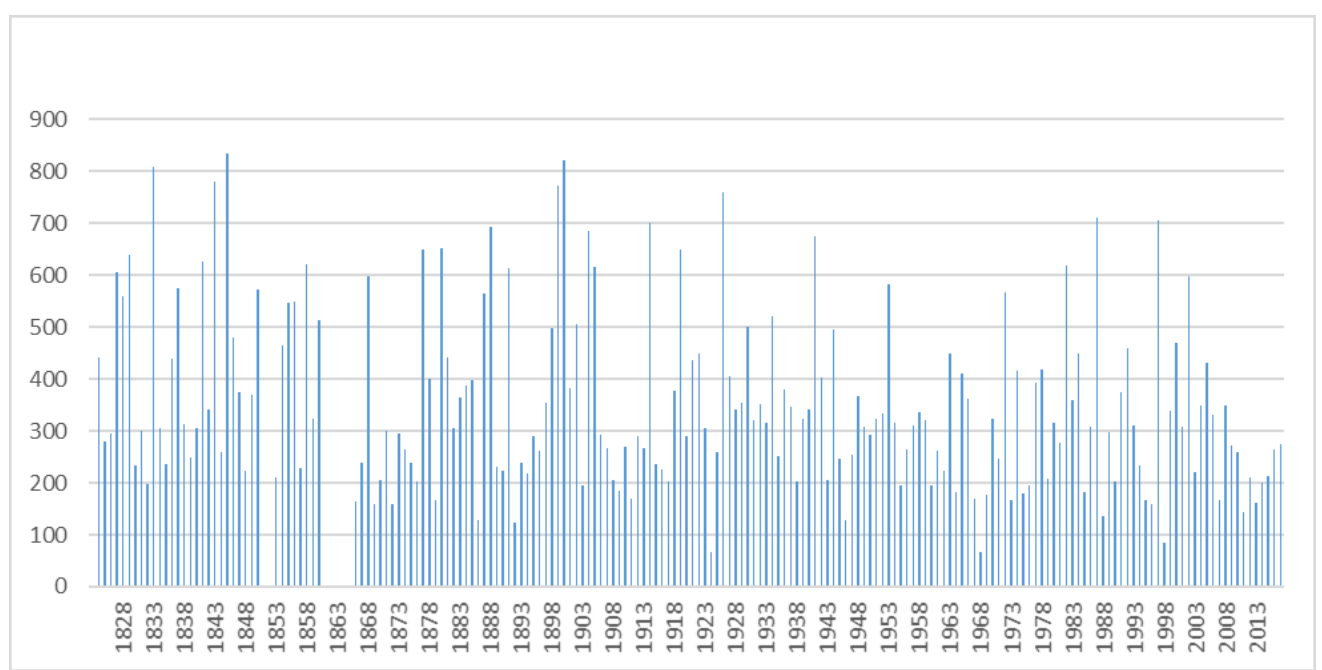

Fuentes: Sociedad Nacional de Agricultura (Chile), Anuario Estadístico de la República de Chile, Dirección Meteorológica de Chile.

Anticipándose a la catástrofe que en parte provocaría la falta de precipitaciones, el diario El Mercurio indicaba que el resumen meteorológico del mes de febrero de 1924 advertía, basándose en cálculos matemáticos asociados al promedio de temperatura del verano, que había "más de un 80 por ciento de probabilidades de que el año en curso sea seco y muy frío, a lo menos en la zona central" $^{\prime \prime}$. Los reportes semanales del 23 y 30 de junio de 1924 profundizaron en la preocupante situación de sequía que afectaba a la zona central del país. El 23 de junio en la sección Tiempo de 
El Mercurio se señalaba: "muy justa es la alarma que causa a los agricultores de la zona central, especialmente a los dueños de fundos de rulo la prolongada sequía del presente año" 9 .

Ya con los datos del año completo, para el agrónomo Carlos Henríquez, Director del Instituto Central Meteorológico y Geofísico de Chile,

"El año 1924 es un año enteramente anormal y por lo tanto, interesante. Durante el invierno se observan en la zona central las temperaturas mínimas más bajas desde que hay observaciones, $y$, respecto de las lluvias, tanto en el norte como en las provincias centrales la sequía fue extrema"10.

Por su parte, el naturalista John A. Wolffsohn observó, después de una serie de excursiones que realizó entre los meses de septiembre y diciembre de 1924, "el progresivo desaparecimiento de los animales silvestres que habitaban los cerros y las llanuras afectadas por la sequía" (Wolffsohn, 1924: 126).

Según las observaciones de Wolffsohn,

"Los mamíferos más pequeños, menos movibles que las aves, careciendo en absoluto de su alimento normal han muerto de hambre casi por completo... Con la vegetación han desaparecido muchas especies de insectos juntos con las aves que de ellos viven. No es exagerado calcular en un $50 \%$ la muerte de árboles de bosques y cerros, junto con la total desaparición de los arbusto de toda clase.... Los campos han quedado con mucho menos de una cuarta parte de su dotación de ganado mayor y menor. Uno de los animales domésticos más afectado por la sequía es la abeja. En muy pocas partes ha podido acumular suficiente cantidad de miel para pasar el próximo invierno" (Wolffsohn, 1924: 127).

Por su parte, el ingeniero agrónomo Augusto Opazo planteaba que las exiguas precipitaciones dificultarían la pervivencia de las semillas sembradas en más de 25 mil hectáreas de terreno, situación que se traduciría en la falta de pasto para sustentar la producción de ganado, especialmente de ovejas y cabras". A su juicio, urgían esfuerzos mancomunados entre el Gobierno y los agricultores para subsanar esta pesarosa circunstancia. Asimismo, el propietario de un fundo en la localidad de Quillota también evidenciaba los perjuicios de las insuficientes precipitaciones manifestando que: "Las siembras de los fundos de la costa que se riegan únicamente con las aguas del tiempo, están ya totalmente perdidas y esta pérdida alterará considerablemente los precios de los productos, haciendo así más difícil la vida de las familias que viven de escasas y fijas entradas mensuales."12 Poco días después, el agricultor José Más escribía una carta al agrónomo jefe de Santiago en la cual solicitaba ayuda técnica para la mantención de semillas y también para la elaboración de pronósticos más certeros respecto a las posibilidades de lluvias ${ }^{13}$.

\footnotetext{
El Tiempo, resumen de la semana. El Mercurio, Santiago, Chile, 23 de enero de 1924, p. 15.

Dirección General de Servicios Agrícolas, Anuario Meteorológico de Chile de 1924, Santiago, Chile, 1926

"El año seco ocasionará incalculables pérdidas". La Unión, Valparaíso, Chile, 9 de julio de 1924, p. 15.

"La sequía del presente invierno". La Unión, 24 de julio de 1924, p. 7.

"Los efectos de la sequía de la región". La Unión, 2 de agosto de 1924, p. 7.
} 
Para el mes de julio, ya era posible percibir "un alza de precios en productos alimenticios de primera necesidad, por ser papas, cebollas, frutas, verduras y carne"14. Según los comerciantes reporteados por el diario La Unión las principales causas de la carestía eran la ausencia de precipitaciones y el alza de los fletes ferroviarios ${ }^{15}$. A estos factores se sumaba la inoportuna llegada de las cosechas hacia las plazas consumidoras, puesto que los productos agrícolas permanecían abarrotados en las estaciones durante meses, "impidiendo que la demanda diaria por dichos artículos de consumo pudiese ser absorbida"16. Consecuentemente, el malestar entre obreros y empleados se hacía notar al constatar que el valor de los alimentos de primera necesidad comenzaban a sufrir ascensos aun imposibles de dimensionar. Sin embargo, denunciaban, los ricos "encerrados en sus mansiones, no escucharan el gemido lastimero de las viudas y de los niños, ni las airadas protestas de las masas enloquecidas por el hambre"17.

Si bien la alarma estaba instalada, algunas voces vinculadas a los empresarios agricultores, sostenían que la sequía no causaría estragos como los previstos, puesto que en las regiones sureñas las lluvias habían alcanzado niveles normales para el invierno del año en curso. Según esta postura, la ausencia de agua sólo tendría efectos desfavorables en el norte, y, pese a este escenario, habría suficiente producción de cereales para abastecer a todo el territorio nacional e incluso para destinar una porción de ésta a la exportación, así lo afirmaba al menos un comerciante porteño entrevistado por La Unión ${ }^{18}$. No obstante, un agricultor rechazó esa posición y señaló que los temores eran fundados, argumentando que las cantidades de lluvias medidas en el sur estaban siendo considerablemente menores en comparación a años precedentes al tiempo que se vislumbraba un alza generalizada de precios para $1925^{19}$.

En estas circunstancias, el 31 de julio de 1924, se realizó en la sede de la Unión de Empleados de Chile una reunión de su directorio con el objetivo de tratar y analizar el problema de la sequía y de la carestía de artículos de primera necesidad derivados de la escasez de alimentos que afectaba la zona norte y central del país. En lo concreto buscaban solicitar a las autoridades una ley de carácter transitorio que prohibiese la exportación de cereales, pues la miseria y el hambre se cernía sobre los hogares de los obreros y empleados del país ${ }^{20}$.

Probablemente, no por casualidad, al día siguiente, Abraham Lekie, Diputado Demócrata por Valparaíso, indicaba a la Honorable Cámara:

"Creo que ha llegado el momento de que nuestros legisladores aborden con toda franqueza y valentía el gravísimo problema de la alimentación popular que hoy día se cierne con negros caracteres sobre nuestro país. Es inútil cerrar los ojos, es inútil confiar en lo inesperado; no se divisa una luz que pudiera desviar el curso de la tempestad que con la violencia de un ciclón avanza y no tardará en envolvernos. Por una parte la caída de nuestra

\footnotetext{
"La carestía actual de los productos de consumo diario". La Unión, 11 de julio de 1924, p. 5.

"La carestía actual de los productos de consumo diario". La Unión, 11 de julio de 1924, p. 5.

"La enorme carestía de los productos de consumo de primera necesidad". La Unión, 14 de julio de 1924, p. 13. Ver también, "El pueblo está notificado con un alza en el precio de la carne". La Defensa Obrera, Tocopilla, Chile, 26 de julio de 1924, p. 1.

"Ante la miseria que avanza. La actual sequía y la próxima falta de cosechas". La Federación Obrera, 6 de agosto de 1924.

"La situación alarmante producida por la sequía en el país". La Unión, 27 de julio de 1924, p. 6.

"La situación que se producirá con la sequía del año actual". La Unión, 28 de julio de 1924, p. 1.

“El alza de los artículos producida por la sequía actual”. La Unión, 1 de agosto de 1924, p. 1.
} 
moneda..... El otro factor que nos lleva a situación tan extrema es la terrible condición del año agrícola que empieza y la perdida casi absoluta de las cosechas" ${ }^{\prime 21}$.

A propósito de este último punto, precisaba que las siembras del secano costero, que conformaban la mitad de los cultivos, podían considerarse completamente perdidas para el año agrícola que se iniciaba. Respecto de las siembras de regadío se podrían aprovechar solamente en un cincuenta por ciento pues, "las vertientes de las nieves acumuladas en los años anteriores necesitarán someterse a turnos rigurosos y odiosos para dar un rendimiento mediocre". Por otra parte, muchos terrenos sembrados deberán dedicarse a pastar los ganados que llegaban allí de las tierras de secano en busca de alimento. Lo que sucedía con la producción agrícola, acontecía también con otro artículo de absoluta necesidad: el ganado para el abastecimiento de carne, pues "Chile no produce, no puede producir todavía la carne necesaria para alimentar a su población"22.

Asimismo, sobre el factor monetario y su relación directa con el alza en el costo de la vida, explicaba que "las escasas existencias del país son ávidamente acaparadas por los comerciantes mayoristas en parte para la exportación aprovechando la baja de nuestra moneda y el resto para almacenarla, ya sea con el objeto de enviarlas al extranjero, cuando baje aun más nuestro billete, o para lanzarlas al consumo una vez que su valor sea tres o cuatro veces mayor que el actual"23.

Finalmente, el Diputado por Valparaíso presagiaba críticos momentos sociales si no se actuaba y se tomaban al menos algunas medidas paliativas ante la emergencia que se avecinaba,

Es llegado, pues, el momento, repito, de poner un remedio radical a la situación. No esperemos que el hambre consuma la faz descarnada de nuestros hijos y de las mujeres de nuestro pueblo. No esperemos ver a turbas de famélicos que levanten al cielo puños huesosos y amenazantes, arremolinándose ante el palacio de sus representantes o asaltando los despachos de menestras. Apartemos los ojos de esos pelotones humanos que rehúyen por el fondo húmedo y nauseabundo de un conventillo. Es llegado el momento álgido de tomar medidas de salvación pública ${ }^{24}$.

En estas circunstancias, las colectividades obreras de Valparaíso se unieron para organizar una fuerte resistencia popular contra el encarecimiento de los productos alimenticios de primera necesidad. Se convocó entonces a una asamblea que tuvo como resultado la articulación del "Movimiento Social Pro Alimentación del Pueblo"25, el cual comenzó a celebrar una serie de reuniones con dos objetivos. Por una parte, lograr hacerse visibles como un elemento organizado que pudiese dar soluciones concretas y no transformarse en una simple manifestación de ciudadanos aislados. Por otra, conseguir la promulgación de una ley que prohibiera la exportación de cereales. De esta manera, quedó conformado un Comité de Sociedades Unidas, cuyos miembros se encargaron de llevar acabo diversas tareas y actividades en pos de alcanzar las mencionadas

\footnotetext{
Sesiones del Congreso Nacional. 50 sesión en 1 de agosto de 1924

Sesiones del Congreso Nacional. 50 sesión en 1 de agosto de 1924

Sesiones del Congreso Nacional. 50 sesión en 1 de agosto de 1924

Sesiones del Congreso Nacional. 50 sesión en 1 de agosto de 1924

"El movimiento social pro alimentación del pueblo". La Unión, 15 de agosto de 1924, p.5.
} 
reivindicaciones, fijándose para ello comicios periódicos entre la segunda quincena de agosto y las primeras semanas de septiembre de $1924^{26}$.

En este contexto, los reporteros de El Mercurio conversaron con un obrero y la esposa de un guardián acerca de los efectos de la carestía del pan:

"Yo señor, nos dijo nuestro entrevistado, tengo siete hijos y gasto en pan hoy día alrededor de $\$ 2.40$. Antes gastábamos en el desayudo 0.40 centavos en el almuerzo y en la comida otros tantos o sea un total de un peso vente centavos y ahora este gasto se ha duplicado. Por su parte, la esposa de un guardián, a quien encontramos en los momentos que salía de un establecimiento panadero, nos expresó que con el sueldo que ganaba su marido no podía hacer frente a los gastos ni siquiera de la alimentación de la familia compuesta por seis personas por cuanto solo en pan gastaba cerca de dos pesos"27.

Los reporteros de El Mercurio contrastaron esta realidad con las opiniones de un agricultor quien indicaba, "No hay porque extrañarse de que el precio del trigo haya subido aquí en Chile. Es este hoy día un fenómeno común en todo el mundo, y debo advertirles que en nuestro país ese cereal tiene un precio muy inferior al de otras naciones". El agricultor expresó además que dada la enorme sequía del presente invierno, no era "aventurado pensar que el precio del trigo tendrá que subir cada vez más lo que afectará indudablemente no solo la economía nacional, sino también a la alimentación de las poblaciones como está ya ocurriendo en presencia de la carestía del pan"28.

En octubre de 1924 el agrónomo Augusto Opazo indicaba "la ruina de la agricultura de la costa no debe dejarnos indiferentes y es necesario preocuparse seriamente de su desastrosa situación actual"29. Este pronóstico fue refrendado por las autoridades en febrero de 1925, pues según las estimaciones del recientemente creado Ministerio de Agricultura, en la zona central hasta Curicó, "se necesitaría una cifra no inferior a cuatro o cinco millones de pesos para obviar siquiera en parte la grave situación en que se encuentra la gente de esas regiones y evitar el despoblamiento de los campos y la mortalidad de los niños por falta de alimentación"30.

A principios de diciembre de 1924, El Mercurio informaba que la desocupación obrera había originado la paralización de las faenas agrícolas. En la zona central y norte del país numerosos obreros habían quedado sin trabajo y a medida que se suspendían las faenas nuevos "grupos de hombres pasan a incrementar la masa ya numerosa de los cesantes", por lo que

"la miseria y el hambre empiezan a sentirse en muchos hogares de gente modesta. Vuelve a presentarse el problema de la desocupación obrera en sus formas más inquietantes...

\footnotetext{
26 Véase: “El gran comicio pro alimentación se verificará el martes próximo”. La Unión, 17 de agosto de 1924, p. 13; “La exportación de cereales en la Cámara". La Unión, 16 de agosto de 1924, p. 10; "El gran comicio de ayer pro alimentación”. La Unión, 21 de agosto de 1924, p. 5; "Esta noche celebrará asamblea el Comité de Sociedades Unidas". La Unión, 27 de agosto de 1924, p. 3; "La asamblea de anoche del Comité de Sociedades Unidas". La Unión, 28 de agosto de 1924, p. 5 y "La asamblea de esta noche del Comité de Sociedades Unidas". La Unión, 30 de agosto de 1924, p. 10

27 "Consecuencias de la carestía del pan en la alimentación popular". El Mercurio, Santiago, Chile, 5 de septiembre de 1924, p. 20.

"Consecuencias de la carestía del pan en la alimentación popular". El Mercurio, Santiago, Chile, 5 de septiembre de 1924, p. 20.

"El problema agrícola del día". El Mercurio, Santiago, Chile, 9 de octubre de 1924, p. 3.

Ministerio de Agricultura, Volumen 39, 1925
} 
la alarmante sequía que ha asolado diversas provincias del norte y centro de la República producirá muy pronto la pobreza y aun más la miseria de numerosos poblados y de los pequeños agricultores de esas regiones" ${ }^{\prime 31}$.

En enero de 1925, El Mercurio indicaba que la notable alza de los precios de la carne se debía a "la ruinosa competencia del ganado argentino en los años 1922 y 1923, y luego este año (1924), por la enorme crisis del forraje que se debe a la sequía extraordinaria, la más extrema de que haya memoria desde que se lleva estadística de las lluvias en Chile" ${ }^{\prime \prime 2}$. Entre las medidas, se solicitaba rebajar los fletes ferroviarios para el transporte de artículos de primera necesidad. Por su parte, indicaba que los alcaldes de las comunas de Matanzas, Rosario y La Estrella habían realizado una presentación a la Junta de Gobierno en la que solicitaron trigo $u$ otros cereales para alimentar a sus 25.000 habitantes. Además, requirieron una moratoria por dos años en especial las deudas hipotecarias y distintas facilidades de crédito ${ }^{33}$.

Posteriormente, el 4 de junio de 1925, el Ministerio de Agricultura informaba que en las localidades del secano costero de La Estrella y Rosario los pequeños agricultores habían "sido afectados en forma extraordinaria en la sequía del año último a tal punto que muchos de estos pequeños agricultores se encuentran casi en estado de miseria". Mientras que seis días después, el ministerio indicaba "ya ha comenzado en forma alarmante la perdida de animales en la zona norte"34.

De acuerdo con los antecedentes recopilados por Rosa Urrutia y Carlos Lanza, la sequía experimentada por el país en 1924 habría significado que entre Coquimbo y el Maule se produjeran, por lo menos, un millón de quintales menos de trigo. Sólo en la provincia de Coquimbo desaparecieron doscientos mil ovejunos, doscientos cincuenta mil caprinos y veinte mil vacunos, y las perdidas de trigo alcanzaron a ciento treinta quintales métricos y en el resto de la zona afectada de un setenta por ciento de la producción normal, en terrenos de secano y de un veinte por ciento de los terrenos regados. La sequía afectó la disponibilidad de pastos para los animales y de agua para siembras provocando un éxodo de los campesinos hacía los asentamientos humanos y centros urbanos, "pero solo cuando los niños ya se estaban muriendo de hambre y no quedaban más que raíces y ratones para engañar al estomago" (Urrutia y Lanza, 1993).

\section{El estado nacional, la crisis política, económica y social y las matanzas obreras de 1925.}

Una situación inesperada como lo era la extraordinaria sequía que enfrentaba el país en 1924, se sumaba al cuadro de extrema crisis económica, política y social que agobiaba a los chilenos y sus familias tras la progresiva desaparición de la renta salitrera y los consecuentes problemas provocados por las fluctuaciones del comercio internacional. Frente a la escasez de divisas y de precipitaciones, $y$ ante los estragos que causaban las malas cosechas que estaba originando la

\footnotetext{
"La desocupación obrera que ha originado la paralización de las faenas agrícolas". El Mercurio, Santiago, Chile, 4 de diciembre 1924, p. 7. Ver también: "La tragedia de la sequía en los campos". La Defensa Obrera, Tocopilla, Chile, 11 de diciembre de 1924, p. 2.

"El mercado de la carne en 1924". El Mercurio, Santiago, Chile, 1 de enero de 1925, p. 29.

"Medidas que se solicitan para hacer menos graves las consecuencias de la sequía". El Mercurio, Santiago, Chile, 7 de enero de 1925, p. 17.

Ministerio de Agricultura, Volumen 39, 1925.
} 
sequía de 1924 en la alimentación popular y de los sectores medios, Abraham Lekie, Diputado Demócrata por Valparaíso, recogiendo parte de las propuestas de la Unión de Empleados de Chile, presentó un proyecto de ley de dos artículos los cuales indicaban 1) Suspéndase, temporalmente mientras nuestro cambio internacional se mantenga a menos de nueve peniques, todo derecho de importación al ganado que entre a nuestro país. 2) Prohíbese, por el término de ocho meses, a contar del primero de septiembre de 1924, la exportación de los siguientes artículos: a) trigo y sus derivados, harina, trigo, mote, sémola, etc.; b) cebada; c) frejoles; d) maíz y morocho; e) arvejas, lentejas y garbanzos ${ }^{35}$.

Apoyando la propuesta, su correligionario, el Diputado Juan Pradenas Muñoz, indicaba que "estos artículos han experimentado un alza considerable y extraordinaria, sobre todo el trigo y demás artículos derivados de la agricultura. En Chile hasta hace poco, el quintal métrico de trigo valía \$30. En Santiago hoy día vale más de cuarenta. Hay opiniones muy valiosas que afirman que el trigo llegará a valer mucho más de $\$ 50$ el quintal, y que, por consiguiente, se va a encarecer enormemente el precio del pan..... me parece que el Gobierno debe poner mano de hierro para impedir que se envíen al extranjero los artículos alimenticios, particularmente el trigo, la harina y los frejoles, a fin de evitar que nos quedemos en casa sin nada" ${ }^{36}$.

No obstante, una opinión indiferente ante la emergencia de la sequía tenía el Ministro de Hacienda, Enrique Zañartu Prieto, quien planteaba que era grave que un país que veía descender su cambio evite

"la salida de productos que tienen que determinar una saludable influencia para entonar nuestra moneda... ese es el peligro de dejar dentro del país el exceso de producción. Ello tiene muchos inconvenientes: primero a este que me vengo refiriendo, sobre el cambio internacional; y segundo, el descorazonamiento de muchos productores de estos artículos de exportación" ${ }^{\prime 37}$.

Sin embargo, refutando la indolencia del Ministro de Hacienda, el Diputado Pradenas respondió,

"por sobre toda consideración relativa a los productores, tenemos la obligación de velar por el bienestar del pueblo, y si el pan sube al doble de precio, indudablemente que el pueblo va a sufrir, que los obreros no podrán pagar a dos pesos el kilo de harina y tendrán que venir trastornos, huelgas y perjuicios muy superiores a los que tendríamos con prohibir la exportación de esos artículos, con lo cual repito, los perjudicados sólo serían algunas grandes firmas, grandes acaparadores y grandes productores. El señor ministro que conoce bien este asunto, sabe que a esta fecha, que ya en julio, la casi totalidad de los agricultores sobre todo los pequeños agricultores han vendido todos sus productos a las casas extranjeras, a los grandes acaparadores, que los tiene en su poder y los envían al extranjero para venderlos a precios exorbitantes debido a la escasez de este articulo por las malas cosechas en Rusia y otros países productores" ${ }^{38}$.

\footnotetext{
Sesiones del Congreso Nacional. 50 sesión en 1 de agosto de 1924

Sesiones del Congreso Nacional. 50 sesión en 1 de agosto de 1924.

Sesiones del Congreso Nacional. 50 sesión en 1 de agosto de 1924.

Sesiones del Congreso Nacional. 50 sesión en 1 de agosto de 1924.
} 
En su discurso, después de sopesar los efectos de la sequía y luego de una serie de consideraciones relacionadas con el supuesto bienestar de los sectores populares y los privilegios de ciertos sectores, el diputado Juan Pradenas Muñoz terminó señalando "de manera que ruego al señor Ministro de Hacienda que, velando por los intereses del pueblo, impida que el hambre se haga presa de los trabajadores de este país en un futuro no muy lejano, pero que ya se ve venir" 39 .

Prácticamente un mes después, el 3 de septiembre de 1924, cuando en vez de tratarse los sueldos de las instituciones armadas los parlamentarios discutieron un alza en su propia dieta, los militares hicieron sonar sus sables en el Congreso Nacional exigiendo mejoras salariales y la aprobación de las leyes sociales ${ }^{40}$. Mas allá de los agudos conflictos estructurales por los cuales atravesaba el país ¿Es mera coincidencia que esta coyuntura tan crítica se provocase justamente cuando la sequía y el alza de los alimentos eran más que evidentes e inevitables? Tras los problemas existentes, la gran sequía ya estaba afectado los niveles de vida de la población del país, encareciendo la alimentación de las familias populares y mermando los salarios de los obreros; pero también de los soldados rasos y de baja graduación y al parecer incluso de los parlamentarios, según se desprende de sus discusiones por intentar alzar sus propios emolumentos. Esto habría provocado un fuerte malestar entre los uniformados quienes decidieron manifestarse en el Congreso Nacional.

Frente a la amenaza militar, las instituciones civiles aprobaron rápidamente las leyes sociales el 8 y 9 de septiembre. No obstante, el 11 de septiembre de 1924, se instaló una Junta de Gobierno presidida por el general Luis Altamirano que decretó la disolución del Congreso. Pese al golpe, evidentemente, los problemas suscitados a raíz del encarecimiento y la hambruna no hicieron otra cosa que persistir. Abogando por la probidad de quienes integraban la más alta cúpula de poder, las organizaciones populares solicitaron a la nueva autoridad una urgente intervención ${ }^{41}$. La acusación iba dirigida contra los comerciantes, a quienes se les responsabilizó por establecer precios abusivos en productos tan elementales como el pan y la leche:

"Como lo decían Uds. en una publicación anterior, los comerciantes escudados en la desconfianza de la Administración caída y en la desvalorización de la moneda nacional, elevaron hasta la exageración el precio de casi todos los productos y mercaderías, al extremo que en las ventas al por menor de los almacenes y despachos, que es donde se surten la gran masa popular, ya son muy raras las especies de abarrotes que pueden ser adquiridos por veinte centavos." ${ }^{\prime 2}$

Respecto del encarecimiento de la carne en Valparaíso, las denuncias apuntaban a los proveedores del Matadero, quienes habían fijado precios exageradamente altos ${ }^{43}$. La sequía así se transformaba en un buen negocio al vender a un precio exagerado los stocks existentes. De acuerdo con El Mercurio la carne había "experimentado un alza de precio que sería la única en el país sino

\footnotetext{
Sesiones del Congreso Nacional. 50 sesión en 1 de agosto de 1924

"Significado y antecedentes del movimiento militar de 1924", Historia, No11, Santiago, 1974.

"Acción del nuevo gobierno ante la carestía de los consumos". La Unión, 19 de septiembre de 1924. Pp. 5.

"Quejas del público por el mantenimiento del alza de los consumos". La Unión, 21 de septiembre de 1924, p. 5.

Véase "El encarecimiento de la carne en Valparaíso". La Unión, 22 de septiembre de 1924, p. 5; "El encarecimiento de la carne en Valparaíso". La Unión, 24 de septiembre de 1924, p. 7 y "El problema de la carne en Valparaíso". La Unión, 27 de septiembre de 1924, p. 8.
} 
existiera otra semejante en el año $1890^{\prime \prime 4}$. Ante la emergencia, los militares optaron por aprobar el Decreto Ley 17 del 30 de septiembre de 1924, que suspendió por el término de seis meses el aumento del cincuenta por ciento sobre los derechos de internación al ganado vacuno y ovejuno.

Por otra parte, entre septiembre y octubre se transportaron para proporcionar forraje, desde la zona centro-norte al sur, 33.699 animales entre vacunos, caballares, ovejunos y cabríos ${ }^{45}$. Poco después, el 17 de noviembre, el Ministerio de Agricultura solicitó a los Ferrocarriles del Estado "una rebaja de $25 \%$ de las tarifas que actualmente están vigentes para el transporte de abonos y una rebaja de fletes para los artículos de primera necesidad que vengan del sur hacia el norte... Con ello se reduciría en gran parte los efectos que tendrá que producir en la zona central la disminución considerable de las cosechas por falta de lluvias" ${ }^{\prime \prime 6}$.

No obstante, el malestar prosiguió a través de innumerables manifestaciones. El 23 de enero de 1925, Carlos Ibáñez y Marmaduke Grove derrocaron a la Junta Militar pidiendo el retorno de Alessandri y estableciendo un gobierno provisorio dirigido por Pedro Pablo Dartnell (Charlin, 1970). La profunda crisis se manifestaba en la disolución del Congreso Nacional, el exilio del presidente, la irrupción de las facciones militares y sus disputas por el poder, pero también en el descontento social extremo producto del alza en el costo de los alimentos provocados por la sequía extrema que afectaba al territorio centro sur del país.

Ante la incertidumbre de una posible hambruna y, pese a la intervención militar, la agitación social no cesaría sino más bien se incrementaría. Las medidas paliativas reactivas estaban dando escasos resultados. Peter DeShazo contabiliza sólo en Santiago y Valparaíso cincuenta y cuatro huelgas entre enero y mayo de 1925, e indica, acorde con nuestra argumentación, que "los trabajadores urbanos iniciaron una ola de huelgas para contrarrestar el aumento en el costo de la vida durante esos años.... Muchos líderes obreros sintieron que el momento revolucionario había llegado" (DeShazo, 2007: 299).

En este contexto, el 30 de enero de 1925, en Valparaíso, los habitantes de los conventillos de ese puerto convocaron a una "huelga de los arrendatarios", en la cual treinta mil manifestantes votaron para pagar solo la mitad de sus arriendos. En Santiago, el 8 de febrero, se reunieron ochenta mil personas. La magnitud que adquirió el movimiento de arrendatarios obligó al gobierno a aprobar un decreto ley de la vivienda conocido como Ley de Arriendos. Pese a lo anterior, a fines de febrero los lideres de las ligas de arrendatarios de Valparaíso y Santiago solicitaron el no pago de arriendos por viviendas insalubres.

\footnotetext{
44 "La carestía de la carne amenaza de hambre al país". El Mercurio, Santiago, Chile, 26 de septiembre de 1924, p. 17. Ver también: "Grave crisis ganadera e impuesto al ganado argentino". El Mercurio, Santiago, Chile, 23 de septiembre de 1924, p. 7. "En presencia del problema de la carne". El Mercurio, Santiago, Chile, 27 de septiembre de 1924, p. 14. "En la mañana de hoy visitará el Matadero el Intendente Municipal". El Mercurio, Santiago, Chile, 3 de octubre de 1924, p. 15. "¿Quiénes son los responsables de la carestía de la carne?". El Mercurio, Santiago, Chile, 8 de octubre de 1924, p. 5. "Reventa de carne en el Matadero". El Mercurio, Santiago, Chile, 8 de octubre de 1924, p. 13. "La carestía de la carne". El Mercurio, Santiago, Chile, 10 de octubre de 1924, p. 15. "Buscando la manera de abaratar la vida”. El Mercurio, Santiago, Chile, 24 de octubre de 1924, p. 19. "El problema de la carestía de la carne y la forma en que se expende un buey en los puestos de la Vega Central". El Mercurio, Santiago, Chile, 26 de octubre de 1924, p. 31.

45 "33,699 animales han sido transportados al sur para proporcionarles forraje". El Mercurio, Santiago, Chile, 20 de noviembre de 1924, p. 21.

46 Ministerio de Agricultura, Volumen 39, 1925.
} 
Carlos Vicuña dice: "cómo empezó el fermento no lo sé". Nosotros creemos que, tal vez, frente al alza en el precio de los alimentos, los ya expoliados arrendatarios se veían materialmente imposibilitados de "dejar al casero la mitad de su renta" (Vicuña, 2002: 298). En este sentido, describiendo la jornada del 30 de enero, Carlos Vicuña indica que varias decenas de miles de hombres y mujeres harapientos y una enorme cantidad de otros menos pobres salieron a la calle pública en son de protesta. Los meetings se sucedían. Los discursos predicaban la resistencia franca y resuelta... la ciudad de Valparaíso... se inflamaba revolucionariamente (Vicuña, 2002: 298).

El 5 de febrero el Ministro de Agricultura reconocía la gravedad de la situación al indicar que "las cosechas de cereales han sido nulas en la zona norte y en la región de la costa de la zona central y las de chacarería no podrán sustraerse a la falta de aguas para el oportuno regadío de los cultivos ${ }^{\prime \prime 4}$. En vista que los medios del Estado no permitían una ayuda de carácter general su acción se limitaría a ayudar a los pequeños agricultores o propietarios que no estaban en situación de trabajar sus suelos ni practicar sus siembras y no podían repoblar sus campos del ganado perdido. La ayuda en referencia consistiría "en prestamos en semillas y posiblemente algunos elementos de trabajo" 48 . En estas circunstancias, el 16 de febrero de 1925, los militares aprobaron el Decreto Ley $N^{\circ} 255$ que destinó fondos para proteger a los pequeños agricultores afectados por la sequía.

No obstante, para los redactores de El despertar de los trabajadores, el problema del año era "valor y pan o cobardía y hambre", pues

"Para la clase trabajadora de Chile no se presenta este año como un sueño azul, sino como un año de grandes y cruentas luchas que tendrá que sostener contra la carestía de vida. Las noticias que por la prensa o particularmente, llegan de la zona agrícola y ganadera no son halagadoras sino desastrosas. La gran sequía que ha azotado el centro del país ha causado grandes e irreparables daños a la agricultura. Regiones enteras hay donde la cosecha ha sido casi nula; grandes perdidas ha sufrido la ganadería... según mi concepto el proletariado del salitre debe pedir en un gran comicio simultáneo en la zona salitrera la inmediata construcción del F.C. de Salta a Antofagasta para que el futuro se despedace el odioso monopolio que ejercen los hacendados y ganaderos chilenos, sobre el abastecimiento de la carne y productos agrícolas en la zona salitrera, mercado éste que por no tener competencia remiten a el los hacendados las sobras de la producción agrícola del país: pues lo mejor es mandado al extranjero... Mi opinión es que se celebre un Congreso de asalariados en una de las ciudades de la zona salitrera para tratar este grave problema que se cierne sobre el proletariado del país, y en especial en el del salitre"49.

Paralelamente, ante el movimiento social que se gestaba y manifestaba a través de distintas formas como la huelga de los arrendatarios o los llamados a la rebeldía en el norte salitrero, el gobierno respondió el 2 de marzo de 1925 por medio del Decreto Ley N²85 del Ministerio del Interior que declaró en estado de sitio las provincias de Santiago, Valparaíso y Aconcagua. 
En estas circunstancias críticas, entre el 8 y 11 de marzo de 1925, se organizó el primer Congreso Constituyente de Asalariados de Chile, el cual entre sus demandas exigió una nueva constitución política (Salazar, 2009; Grez, 2016).

Pese al regreso de Arturo Alessandri el 20 de marzo de 1925, prosiguieron las protestas y mítines populares. Los obreros se hallaban perturbados por los sucesos políticos, por los abusos patronales, por el cierre de las oficinas salitreras, para miles de proletarios pampinos única fuente de trabajo, y por las inusitadas alzas en el costo de la vida producto de la especulación que provocaba la escasez originada por la sequía. Es presumible que ante la dependencia de productos alimenticios enviados desde la zona central del país, su carestía y el alza en los precios incrementaran el costo de la vida, sumergiendo en el hambre y el malestar a miles de familias de los obreros salitreros. Al parecer las carencias alimenticias y la incertidumbre socioeconómica hicieron subir la efervescencia social a niveles inusitados desencadenando la preocupación de las autoridades.

Fue entonces cuando se produjo la brutal masacre de Marusia, donde se exterminó a sus pobladores en medio de confusos incidentes que involucraron la venganza de los trabajadores ante un despiadado ingeniero británico que acostumbraba a azotar a sus obreros, junto con una serie de negociaciones infructuosas que culminaron con la muerte de más de quinientas personas, aproximadamente el veinte por ciento de los dos mil cuatrocientos habitantes de aquella oficina salitrera.

Los refuerzos del ejército chileno habían llegado al mando del coronel Pedro Schultz. Atacaron Marusia en medio de la noche y ametrallaron a sus habitantes sin remilgos ni resquemores. Había que dar el ejemplo. Un grupo de trabajadores fue capaz de montar una defensa apresurada lanzando cartuchos de dinamita sobre el avance de las tropas. Sin embargo, toda resistencia fue infructuosa. Los mineros sobrevivientes escaparon con sus familias hacia las altas montañas. Los que huían eran alcanzados por balas en sus espaldas originando el vocablo pampino "palomear" (Harambour Ross, 1998).

Esta masacre puso fin a la huelga generalizada de inmediato, pero el conflicto siguió latente y estalló nuevamente en menos de dos meses. Ante la carestía y los estragos que al parecer efectivamente estaba provocando la severa sequía del año anterior, tal como lo habían presagiado los diputados demócratas y radicales, las instituciones gremiales de lquique y de las oficinas salitreras del interior acordaron un paro general exigiendo mejoras salariales, las cuales se tornaban cada vez más imprescindibles frente a la escasez de alimentos y el alza en el costo de la vida.

Así lo manifestaba, el 6 de mayo de 1925, el Ministro de Agricultura Claudio Vicuña Subercaseaux, quien reconocía que

“La sequía del año último, que afectó gran parte de la zona central del país, ha traído como consecuencia el encarecimiento de los artículos de subsistencia, especialmente de los cereales. El ministerio a mi cargo se encuentra empeñado en adoptar las medidas que crea conducentes a obtener el abaratamiento de la vida y para este fin estimo que una de las medidas primordiales sería la de traer con fletes baratos artículos de primera necesidad a aquellos centros poblados donde hubieran sufrido el aumento mayor de los precios de venta" ${ }^{\prime \prime}$.

\footnotetext{
Ministerio de Agricultura, Volumen 39, 1925.
} 
Pocos días después, el Ministro de Agricultura insistía que la secretaría de Estado a su cargo tenía conocimiento de que la cosecha de papas en la zona central del país había sido inferior a la de años anteriores debido "principalmente a la sequía que afectó el año último a esta zona"51.

Asimismo, tal como lo había adelantado el diputado Pradenas, Claudio Vicuña Subercaseaux señalaba:

"La exportación de este producto en los meses corridos del año en curso ha sido muy superior a la exportación hecha en igual período del año 1924, lo que ha traído un aumento considerable de este cereal en el mercado. El alza del precio del producto en referencia se debe a los intermediarios que aprovechándose de la escasez del articulo y su fácil exportación lo han encarecido en forma exagerada"52.

A juicio del ministro, la papa era uno de los productos de mayor consumo en el país y era también de imprescindible necesidad en todos los hogares, aun en los más modestos, por esto era necesario que se adoptasen medidas conducentes al abaratamiento de este alimento, lo cual implicaba finalmente una disminución en el costo de la vida. En ese sentido, el 11 de mayo de 1925, el ministro propuso la prohibición de exportar papas hasta el $1^{\circ}$ de diciembre de 1925. La medida tomada por las autoridades fue ampliamente resistida por la Cámara de Comercio y la Sociedad Nacional de Agricultura ya que, a juicio de estas entidades, "la prohibición de exportar productos de la agricultura es contraria a las garantías de ofrece la Constitución Política del Estado" ${ }^{53}$.

No obstante, ante las circunstancias descritas, el gobierno consideró que en el contexto en que vivía el país era antipatriota considerar sustraer del consumo nacional artículos indispensables para la subsistencia de los sectores populares. A juicio del ministro Vicuña, las medidas "adoptadas no iban dirigidas en ningún caso al productor sino que a aquellos que con espíritu de lucro tratan de aprovecharse de una situación por demás difícil para el pueblo en general debido a la sequía del año último que ha hecho escasear productos de primera necesidad" ${ }^{54}$.

Con todo, pese a las buenas intenciones y ante la amenaza de un estallido social, incubado por años de explotación pero agudizado por un año de sequía extrema particularmente difícil por el alza en el costo de la vida, el Ministro de Guerra, Carlos Ibáñez no vaciló al enviar un telegrama el 27 de mayo de 1925 advirtiendo a Florentino de la Guarda acerca de un movimiento subversivo de carácter comunista que se incubaba en las localidades salitreras y otorgándole amplias facultades (Durán Gutiérrez, 2011; Harambour Ross, 1988). De la Guarda clausuró todas las imprentas donde los obreros editaban sus hojas de protesta y les acusó de hacer fracasar el plebiscito sobre la frontera norte. Esto sirvió de pretexto para acusar a los alzados de antipatriotas, ácratas sin ley ni respeto por los sagrados vínculos de la patria, enardeciendo así la persecución policial con detenciones masivas de los obreros salitreros.

Ante los abusos de las autoridades y patrones, las organizaciones obreras acordaron un paro generalizado. La huelga implicó la toma de 124 oficinas salitreras, además de la paralización del 
puerto de Iquique, de los ferrocarriles y de los conductores de carretas. Inmediatamente el intendente Recaredo Amengual movilizó al ejercito para proteger el ferrocarril y las fuerzas navales fueron rápidamente transportadas al norte por el gobierno, enviándose refuerzos a los puertos de Iquique, Pisagua y Mejillones en los buques de guerra Zenteno, O'Higgins, Lynch, Riquelme y Williams Rebolledo. Según Carlos Vicuña, el intendente Amengual, "siempre ebrio, comunicó a Ibáñez las espeluznantes noticias de la pampa e Ibáñez por si y ante si lo autorizó para reprimir y sofocar la revolución a sangre y fuego" (Charlin, 1970).

En las oficinas salitreras de Alto de San Antonio, Pontevedra, Barrenechea, Felisa, Santa Lucia, Vigo, San Enrique, La Coruña y otras, se produjeron gravísimos y brutales encuentros entre los proletarios armados con piedras, palas, herramientas y dinamita contra los carabineros y el ejercito, equipados con armamentos de grueso calibre, ametralladoras, fusiles y sables ${ }^{55}$.

En este contexto, a los oficiales de los regimientos Granaderos, Carampangue y General Salvo se les encomendó la tarea de recuperar las oficinas salitreras a sangre y fuego y de tomar las necesarias medidas para mostrar un escarmiento ejemplificador en contra de los rotos alzados e insumisos.

Los oficiales se tomaron muy en serio la orden de sus superiores. No era tolerable una revolución en Chile. Había sin duda que dar un escarmiento ejemplar. En La Coruña, el 25 de junio de 1925, no quedó hombre ni mujer ni niño o niña con vida. Solo en ese lugar se han calculado en más de 2.000 los muertos. Pese a las banderas de rendición de los proletarios alzados y sus familias, no se tomaron prisioneros sino más bien se les ejecutó sin piedad en una de las matanzas obreras más ominosas y escarnecedoras de la historia de Chile. Como dijo el destacado médico Carlos Charlin Correa, contemporáneo a los hechos, las matanzas de "La Coruña, Alto de San Antonio, Felisa y otros lugares de esa pampa de la desgracia son paginas que horripilarían a un escritor de novelas de terror" (Charlin, 1970: 118). En este sentido, Vicuña indicó que

“los tenientes y capitanes, por saña y placer, fusilaron a mansalva hombres, mujeres y niños, en grupos, al montón, y después aisladamente a todo aquel que los pulperos señalaban como subversivo o rezongón. No dieron cuartel, no recogieron heridos, no perdonaron la vida a nadie, el que huía de las calicheras era alcanzado por las balas. A muchos infelices los hacían cavar sus propias fosas y los fusilaban en seguida sin piedad alguna" (Vicuña, 2002: 322).

El 10 de julio de 1925 las autoridades ministeriales señalaban que ya había comenzado en forma alarmante la perdida de animales en la zona norte (Vicuña, 2002). Posteriormente, el 23 de julio se establecieron requisitos para ingresar animales al país y el 23 de septiembre de 1925, por medio del decreto ley No 538, se suspendió el pago de los derechos de internación del ganado argentino. Finalmente, el 14 de octubre se solicitó el "abaratamiento de los fletes ganaderos" y el

\footnotetext{
55 El pueblo «Alto de San Antonio» era en 1925 el más importante de la pampa salitrera; contaba con servicios administrativos públicos: Subdelegación, Juzgado de Letras, Correos y Telégrafos, Registro Civil, Parroquia, Autoridad Comunal, Cuerpo de Bomberos, Prefectura Policial, Camal (matadero de ganado para carne), Cantón Militar, y otros. Además circulaba un periódico local, «El Correo de San Antonio». En 1918 la Escuela Pública No 28, mixta, tenía por preceptora a Amelia Guerrero Bahamondes, propietaria con 12 años de servicio; El Curato lo atendía el Presbítero Arturo Valenzuela.
} 
9 de noviembre "ante el encarecimiento de los artículos de primera necesidad", se estableció la "Sociedad de Ollas Infantiles de Santiago" (Vicuña, 2002).

En vista de los antecedentes expuestos, nos preguntamos nuevamente, entonces, ¿es mera casualidad o coincidencia que las manifestaciones de los conventilleros de Valparaíso y de los trabajadores pampinos del norte que culminaron con dos de las matanzas obrero-salitreras más paradigmáticas se hayan producido precisamente en el momento más álgido de la crisis política, pero también -cuando producto de los efectos de la extraordinaria sequía de 1924- era evidente que escaseaban los alimentos, es decir, en el instante de la carestía absoluta, del temor a la hambruna generalizada y, por parte de las autoridades, del momento en que había que dar una señal ejemplar con el objetivo de contener una posible sublevación mayor de los sectores populares cada vez más afligidos y apremiados por el alza en el costo de la vida? ¿fue el miedo a una sublevación proletaria ante el hambre que se esparcía por la pampa salitrera la causa de las matanzas de 1925 ?

Tal como lo había anticipado el periódico comunista La Federación Obrera el 21 de julio de 1924,

“La malas cosechas afectan a la población entera y esta vez habrán de sentir sus efectos con mayor intensidad los habitantes de las provincias áridas y estériles, como Tarapacá y Antofagasta, donde hay miles de habitantes que han de tener que pagar precios exorbitantes por los productos. Y debe tomarse en cuenta que no sólo es en el curso del año cuando se han de sentir estos pésimos efectos, pues que ellos se hacen extensivos a fechas venideras.... Estamos, pues, a un paso del momento en que empezará el hambre a hacer sus estragos, a un minuto de empezar la dolorosa representación real del hambre y la miseria en el escenario del país" ${ }^{\prime \prime 6}$.

\section{Consideraciones finales}

Las hambrunas y sus efectos económicos, políticos y sociales han sido abordados desde distintas perspectivas enfatizándose las crisis ambientales producidas por eventos climáticos extremos, el crecimiento demográfico, la urbanización y la falta de inversión en agricultura. Después de analizar los sucesos acaecidos en Chile, tras la gran sequía de 1924, nuestra perspectiva asume que la escasez de alimentos y las hambrunas obedecen a causas más complejas que no pueden reducirse únicamente a una sequía extraordinaria o bien sólo a los procesos de crecimiento demográfico y de urbanización. Durante la famosa hambruna de Irlanda que ocasionó un millón de muertos en 1846 cronistas describieron como el ejercito escoltaba la exportación de alimentos. En la más grande hambruna registrada en la India en el siglo XIX murieron seis millones de personas mientras arribaban a los puertos ingleses cerca de cuatro millones de toneladas de trigo provenientes de ese país. Durante una gran sequía en la década de 1970 que ocasionó millares de muertos, Burkina Faso exportó millones de dólares en alimentos hacia Ghana y Nigeria. Los ejemplos pueden multiplicarse. Los alimentos han estado disponibles pero es evidente que hay grandes dificultades de acceso no necesariamente derivados de las

56 "Ante el espectro del hambre". La Federación Obrera, Santiago, Chile, 21 de julio de 1924 
sequías locales sino tal vez globales. En el caso de Chile las exportaciones de trigo se incrementaron (Cariola y Sunkel, 1982).

Los eventos climáticos extremos y el consiguiente deterioro de las condiciones de vida no pueden entonces ser explicados "por simples relaciones causales lineales. Se trata de problemas estructurales de un sistema complejo que incluye tanto el sistema ambiental donde se desarrolla la producción, como los grupos sociales que la producen, la economía que los rige y los factores externos que condicionan su actividad" (García, 1988).

En el caso de la crisis socio-política que se originó por el alza en el costo de la vida hacia el segundo semestre de 1924 hay varios factores que actúan en forma concomitante. Por un lado, la crisis ya estructural del sistema político y económico, por otro, las condiciones de vida y laborales de la mayor parte de la población y sus exigencias de mejoras salariales para paliar el alza en el costo de la vida. A este cuadro crítico que se arrastraba por años se sumaba la extraordinaria sequía, pero también la percepción de muchos actores sociales que la exportación o especulación en torno al precio de alimentos claves como el trigo que se consideraban de salvación nacional era "antipatriótica".

Para amplios sectores de la población incluso para parte de los militares gobernantes era incomprensible e irritante que las elites insistieran en la conveniencia de la exportación de alimentos mientras la carestía y el hambre arrasaba con buena parte los hogares del país. Así, junto con la sequía, la indiferencia de las autoridades, de los productores y de los comerciantes ante el alza en el costo de la vida bien pudo haber sido el detonante de un sentimiento de rebeldía mayor que terminó por expresarse en mítines, asambleas, disturbios, huelgas y manifestaciones que culminaron trágicamente con las emblemáticas matanzas de Marusia y La Coruña, pero también, como se ha visto, de muchas otras oficinas salitreras.

\section{Agradecimientos}

Agradecemos el financiamiento del proyecto FONDECYT 1180537 y de CONICYT PIA/BASAL FBO002

\section{Referencias bibliográficas}

ALBEROLA ROMÁ, A. Plagas de langosta y clima en la España del siglo XVIII. Estudios de Historia y Sociedad, 2012, Vol. 33, No 129, p. 21-50.

ARRIERO, M. L. "Los motines de subsistencia en España, 1895-1905". Estudios de Historia Social, $1984, N^{\circ} 30$, p. 193-250.

BeLLemARE, M. F. Rising Food Prices, Food Price Volatility, and Social Unrest. American Journal of Agricultural Economics, 2015, Vol 97, Issue 1, p. 1-21. 
BERESFORD-JONES, David. Los bosques desaparecidos de la antigua Nazca. Estudio de un caso de colapso ecológico y cultural. Lima, Perú: Editorial Antáres, 2014.

BLACK, B.; HASSENZAHL, D.; STEPHENS, J.; WEISEL; G. y GIFT N. Climate change: an encyclopedia of science and history. Santa Barbara, ABC-CLIO, 2013, 4 vols.

CARIOLA, C. y SUNKEL, O. La historia económica de Chile, 1830 y 1930: dos ensayos y una bibliografía. Madrid: Cultura Hispánica del Instituto de Cooperación Iberoamericana, 1982.

CHARLIN, C. Del Avión rojo a la república socialista, Quimantú, 1970.

DESHAZO, P. Trabajadores urbanos y sindicatos en Chile: 1902-1927. Santiago: DIBAM, 2007

DURÁN GUTIÉRREZ, S. Holocausto en la oficina salitrera "Coruña". La olvidada Matanza de Obreros y sus Familias. Iquique, 2011.

FAGAN. B. M. The little ice age: how climate made history, 1300-1850. New York, Basic Books, 2000.

GARCÉS, M. Crisis social y motines populares en el 1900. Santiago: LOM, 2003.

GARCÍA, Rolando. Deterioro ambiental y pobreza en la abundancia productiva. IFIAS, México, 1988.

GREZ, S. De la 'regeneración del pueblo' a la huelga general: génesis y evolución histórica del movimiento popular en Chile (1810-1890). Santiago: DIBAM, 1997

GREZ, S. La asamblea constituyente de asalariados e intelectuales Chile, 1925: Entre el olvido y la mitificación. Revista Izquierdas (Santiago), 2016, № 29, p. 1-48.

HARAMBOUR ROSS, A. Ya no con las manos vacías. (huelga y sangre obrera en el Alto San Antonio. Los "sucesos" de La Coruña. Junio de 1925)". En: ARTAZA, P.; GONZÁLEZ, S.; MIRANDA, G., JILES, S. (editores). A cien años de Santa María de Iquique. Santiago de Chile: Ediciones LOM, 1998.

HAUENSTEIN, S.; HADLEY, S. y CICHON, B. ¿De que se alimenta el hambre? Barcelona: Icaria, 2009.

HSIANG, S.; MEN, K. y CANE, M. Civil Conflicts are Associated with the Global Climate. Nature, 2011, No 476, p. 438-331.

LAMB, H. H. Climate, history and the modern world. London Routledge, 1994, 433 p.

Le ROY LADURIE, E. Historia humana y comparada del clima. México: FCE, 2017, p.517.

PRIBYL, K. Farming, Famineand Plague. The Impact of Climate in LateMedievalEngland. Springer, 2017. https://link-springer-com.pucdechile.idm.oclc.org/content/pdf/10.1007\%2F978-3-319-55953-7. pdf 
ROTBERG, R. \& RABB, T. Climate and history: studies in interdisciplinary history. Princeton University Press, 1981, $280 \mathrm{p}$.

SALAZAR, Gabriel. Del poder constituyente de asalariados e intelectuales: (Chile, siglos XX y XXI). Santiago: LOM Ediciones, 2009.

URRUTIA, R. y LANZA C. Catástrofes en Chile. La Noria, 1993.

VICUÑA, Carlos. La tiranía en Chile. LOM, 2002

WHITE, S.; PFISTER, C. y MAUELSHAGEN, F. The palgrave handbook of climate history. London: Palgrave Macmillan, 2017.

WOLFFSOHN, J.A. Observaciones sobre los efectos de la extraordinaria sequía del año 1924 en la fauna de las provincias centrales de Chile. Revista Chilena de Historia Natural, 1924. 